\title{
Ensino de algoritmos com poemas através do editor Poesia(): Relato de experiência
}

\author{
Soraya R. S. Medeiros ${ }^{1}$, Humberto Rabelo ${ }^{1}$, Tânia C. M. Garcia ${ }^{2}$, Isabel D. \\ Nunes $^{3}$, Felipe G. Medeiros ${ }^{4}$, Angélica F. Medeiros ${ }^{1}$, Daniele S. S. Rabelo ${ }^{5}$ \\ ${ }^{1}$ Departamento de Computação e Tecnologia - Centro de Ensino Superior do Seridó- \\ Universidade Federal do Rio Grande do Norte(UFRN)-Campus Caicó \\ ${ }^{1}$ Departamento de Educação- Centro de Ensino Superior do Seridó- Universidade \\ Federal do Rio Grande do Norte(UFRN)- Campus Caicó \\ ${ }^{3}$ Instituto Metrópole Digital - Universidade Federal do Rio Grande do Norte (UFRN) \\ ${ }^{4}$ Instituto Federal do Rio Grande do Norte(IFRN)- Campus Caicó \\ ${ }^{5}$ Secretaria de Educação à Distância (SEDIS) Universidade Federal do Rio Grande do \\ Norte (UFRN) - Natal - RN - Brasil \\ \{soraya.roberta.js, hrabeloufrn,fgmfrioforte, rabrlodanni, angelicafelixx \}@gmail.com, \\ tania_cristina2005@yahoo.com.br, bel@imd.ufrn.br
}

\begin{abstract}
Techonological fluency highlights among human skills required for new activities of this century. This work aims to report an algorithm teaching experience through poems using Python programming language mediated by Poesia() editor for a target audience of varied ages. Actions followed Problem Based Learning (PBL) methodology, through which Python functions, data types and variabled were studied. Workshop was realized during a Campus Party, where participants could create, read, and interpret poems and transform them in algorithms, developing problem systematic comprehension.
\end{abstract}

Resumo. Dentre as habilidades humanas requeridas para as novas atividades deste século, destaca-se a fluência tecnológica. Este trabalho visa relatar uma experiência de ensino de algoritmos utilizando poemas utilizando a linguagem de programação Python mediado através do editor Poesia() para um público-alvo de diferentes idades. As ações foram baseadas na metodologia Aprendizado Baseado em Problemas (Problem Based Learning - PBL) pela qual foram trabalhados funções da linguagem Python, tipos de dados $e$ variáveis. A oficina foi realizada durante uma Campus Party, onde os participantes puderam criar, ler, interpretar poemas e transformá-los em algoritmos, desenvolvendo a compreensão sistemática de problemas.

\section{Introdução}


VII Congresso Brasileiro de Informática na Educação (CBIE 2018)

Anais dos Workshops do VII Congresso Brasileiro de Informática na Educação (WCBIE 2018)

Muitas pesquisas têm sido realizadas sobre as novas habilidades humanas requeridas para as novas atividades inerentes a este século. Dentre estas habilidades, destaca-se a fluência tecnológica [Batista et al., 2017]. Neste contexto, um relevante aspecto está relacionado ao fato que os indivíduos não precisam apenas consumir novas tecnologias, mas também poderem se tornar autores a partir do desenvolvimento de soluções das suas próprias necessidades tecnológicas. Relacionando tais pontos, destaca-se a habilidade em programação, que possui papel fundamental para a concatenação do Pensamento Computacional (PC). Esta forma de pensamento envolve a resolução de problemas, a capacidade de projetar sistemas e a compreensão básica para a solução de problemas tanto técnico-científicos quanto da vida cotidiana [Wing 2006].

O Aprendizado Baseado em Problemas (Problem Based Learning - PBL) é uma forma de aprender com a utilização de cenários que envolvem problemas da vida real, ou seja, desafia os alunos a aprenderem e trabalharem em grupos na busca de soluções para os problemas do cotidiano [Hou 2014]. Nesta metodologia, os alunos vivenciam a aprendizagem de maneira prática e contextualizada, compreendendo o porquê de suas ações, processos de busca pelo conhecimento, estabelecimento de hipóteses e possíveis soluções na realização das atividades demandadas.

No entanto, desenvolver o PC e consequentemente o domínio da lógica computacional, indispensável para a criação de algoritmos, pode se tornar algo complexo para pessoas que nunca tiveram contato com a área, devido a necessidade de abstração, automação e análise inerente a essas tarefas [Andrade et al., 2013].

Diante do que foi exposto, o desafio de favorecer o desenvolvimento de habilidades cognitivas que facilitem o processo de ensino-aprendizagem de algoritmos passa pela carência em associar estratégias que estejam relacionadas ao cotidiano, de uma forma mais lúdica e adequada aos envolvidos, o que pode ser dificultado de acordo com a faixa etária.

$\mathrm{Na}$ busca por solução para estes problemas, o presente trabalho apresenta o projeto Poesia compilada, que é um Manifesto Literário que propõe a junção de conceitos de algoritmos com a sintaxe do gênero textual poema. $\mathrm{O}$ primeiro relato do uso desse Manifesto para o ensino de Algoritmos encontra-se no trabalho de [Andrade, Medeiros and Medeiros 2017]. Neste sentido, o objetivo desta pesquisa se concentra em relatar uma experiência de ensino de algoritmos utilizando poemas através da linguagem de programação Python, mediado através do editor Poesia(), para um público-alvo de diferentes idades.

\section{Metodologia}

O editor Poesia() ${ }^{1}$ foi utilizado para a aplicação da linguagem de programação Python durante as atividades desenvolvidas, bem como notebooks, smartphones, a fim de que os alunos pudessem realizar quaisquer pesquisas caso tivessem dúvidas ao longo da oficina. As ações foram baseadas na metodologia PBL com a formulação de perguntas específicas, definição e especificação do foco. A oficina com carga horária de $4 \mathrm{~h}$ aconteceu na Campus Party Natal em área aberta ao público no dia 14 de Abril de 2018

1 poesiacompilada.com/editor 
VII Congresso Brasileiro de Informática na Educação (CBIE 2018)

Anais dos Workshops do VII Congresso Brasileiro de Informática na Educação (WCBIE 2018)

e foi ministrada pela aluna Soraya Roberta. A oficina contou com a participação de 15 pessoas, com idade variando entre 16 - 62 anos. Dos participantes, apenas 3 tinham formação na área, os quais ajudaram aos demais a fazerem os algoritmos com poema.

Inicialmente começou-se a suscitar nos alunos o que eles conheciam sobre a estrutura do gênero textual poema. Feito isto, foi explicado aos participantes quais as relações entre a estrutura de um poema e a de um algoritmo. Em seguida, foi explanado a sintaxe da linguagem de programação Python, bem como qual o significado de se utilizar uma função, em específico a função print. Por fim, os participantes produziram poesias compiladas em python utilizando a função print, entenderam o que são variáveis e atribuições, bem como o significado de palavras reservadas, tal como a def. Devido a carga horária disponibilizada pelo evento para a execução da oficina, não foi possível abordar as demais estruturas da linguagem de programação ficando a oficina restrita ao que foi mencionado.

\section{Resultados e discussões}

Ao passo em que os alunos compreenderam o que era a linguagem de programação, bem como a função print, tal como a Figura 1 a), começaram a querer entender exemplos de outras funções, como a input, e como criar uma função como a apresentada na Figura 1 b).

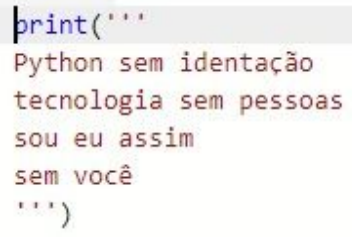

(a)

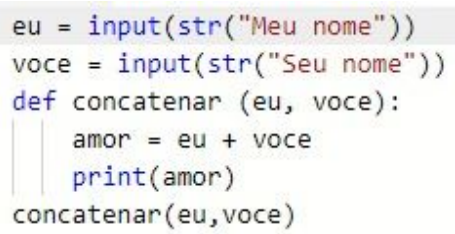

(b)

Figura 1. Utilização da função print. Fonte:Alunos participantes.

Para desenvolverem os algoritmos da Figura 1 a) e Figura 1 b), eles tiveram que pesquisar como fariam para armazenar as palavras e cada verso do poema que estavam criando, chegando ao conceito de variáveis, bem como, quais os tipos de dados existentes e qual a diferença de Python para outras linguagens em relação aos tipos de dados. Ao produzirem os poemas, refletiram sobre o que estavam criando para então escrevê-los em forma de um algoritmo.

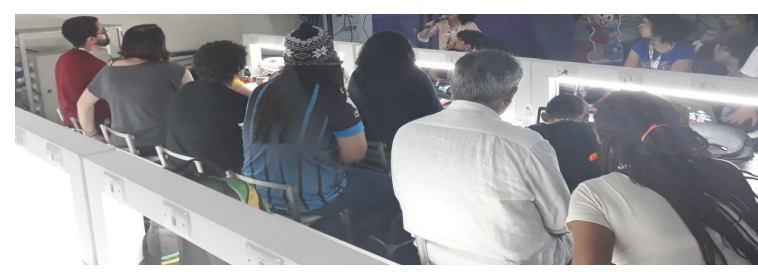

(a)

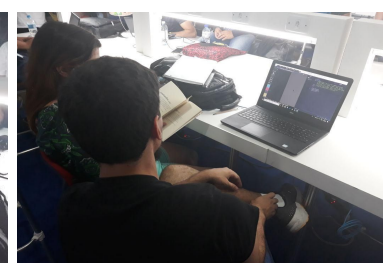

(b)

Figura 2. Participantes da oficina. Fonte: Autores.

Considera-se que a oficina foi bem aceita pelos participantes, uma vez que mesmo tendo outras oficinas sendo realizadas ao mesmo tempo, grande público compareceu, como exposto na Figura 2 a) e Figura 2 b), além disso, conseguiram compreender e produzir 
VII Congresso Brasileiro de Informática na Educação (CBIE 2018)

Anais dos Workshops do VII Congresso Brasileiro de Informática na Educação (WCBIE 2018)

algoritmos com base nos conceitos sobre o gênero textual poema, provando isso por meio das poesias compiladas criadas. O que contribuiu para desenvolverem, dentre outras características, a compreensão sistemática de problemas a partir da formulação de hipóteses e possíveis soluções na realização das atividades. A maior dificuldade encontrada foi a conexão com a internet, pois o evento não disponibilizou a estrutura necessária para ser executada, entretanto, foi rapidamente resolvida pelos alunos que possuíam smartphones com dados móveis e utilizaram para pesquisar e escrever no editor Poesia().

\section{Considerações finais}

Neste trabalho, foi possível observar a aplicação do ensino de algoritmos e programação, uma das estratégias para se trabalhar com o PC, com público de idades variadas, durante a Campus Party Natal em ambiente aberto ao público. Este trabalho inova ao utilizar o gênero textual poema para ensinar algoritmos através da linguagem de programação Python, uma vez que propõe a interpretação de um poema, para se trabalhar com uma das abordagens proposta pelo PC, bem como realizar tal procedimento utilizando PBL.

Neste sentido, a aprendizagem baseada em problemas proporcionou uma intersecção entre os conhecimentos prévios, o objeto de conhecimento e a aprendizagem gerada e constitui-se em metodologia inovadora e motivacional para o ensino de algoritmos, à medida em que o elemento motivador propulsor do engajamento para a aprendizagem foi a demanda a ser

Por fim, para trabalhos futuros, sugere-se a aplicação mais detalhada dos demais conceitos sobre algoritmos com público de idades variadas, por meio da temática desta oficina para que os alunos possam aprender mais detalhes das linguagens de programação e implementação.

\section{Referências}

Andrade, A. P. V., Medeiros, I. G., Medeiros, S. R. S. (2017). Ensino de algoritmos com Poesia Compilada: experiências em turmas iniciais no Bacharelado em Sistemas de Informação. In II Congresso sobre Tecnologias na Educação, p. 523-529.

Andrade, D., Carvalho, T., Silveira, J., Cavalheiro, S., Foss, L., Fleischmann, A. M., ... \& Reiser, R. (2013). Proposta de atividades para o desenvolvimento do pensamento computacional no ensino fundamental. In Anais do Workshop de Informática na Escola (Vol. 1, No. 1, p. 169).

Batista, E. J. S., Silva, L., Leite, C., \& Lima, A. (2017, October). Poredu: um ambiente de programação em blocos. In Anais dos Workshops do Congresso Brasileiro de Informática na Educação (Vol. 6, No. 1, p. 144).

Hou, S. I. (2014). Integrating Problem-Based Learning with Community-Engaged Learning in Teaching Program Development and Implementation. Universal Journal of Educational Research, v. 2, n. 1, p. 1-9.

Wing, J. M. (2006). Computational thinking. Communications of the ACM, 49(3):33-35. 